\title{
Silver Extraction with Sulfide Type Trident Compounds
}

\author{
Keisuke OHTO*, Takuyou YOSHINAGA, Hiroaki FURUGOU, Shintaro MORISADA, \\ Hidetaka KAWAKITA and Katsutoshi INOUE \\ Department of Chemistry and Applied Chemistry, Faculty of Science and Engineering, Saga University, \\ 1-Honjo, Saga 840-8502, Japan
}

(Received January 4, Accepted March 2, 2018;)

\begin{abstract}
A sulfide type trident molecule together with a monopodal compound has been prepared to investigate the extraction behavior of silver. The present trident molecule has a weaker extraction ability than thiol and dithioether derivatives of previously reported tripodal extraction reagents. On the contrary, it exhibited a higher extraction ability than the corresponding monopodal molecule due to the structural effect of the trident framework. Both sulfide molecules did not exhibit any $\mathrm{pH}$ dependency for silver extraction. The trident molecule showed a $1: 1$ stoichiometry (trident molecule : silver), while the monopodal molecule gave a $2: 1$ stoichiometry (monopodal molecule : silver). The coordination site of the trident molecule was confirmed by ${ }^{1} \mathrm{H}-\mathrm{NMR}$ spectra before and after silver loading. The signal shifts for the protons of the methylene groups bounded to the sulfur atoms for the trident and monopodal compounds before and after silver loading were correlated with the formation of complexes. From the comparison of both molecules, the peak shift for the trident molecule included contributions not only from the functional groups but also from the structure of the trident framework.
\end{abstract}

\section{Introduction}

Silver is used as coins, jewelry, and various advanced materials. Recovery of silver from ores or from urban mining is required. The nature of the extraction reagents is important for the separation efficiency using solvent extraction [1]. Silver is one of the precious metals and is typically classified into soft acid [2] and its affinity with soft ligands is strong. Some review articles discuss sulfur-containing reagents [3,4]. Thiocrown ether type ligands were also prepared for soft metals [5-8]. Calixarene- and trident-based extraction reagents not only with soft coordinating atoms but also hard atoms have been prepared for silver extraction by our group [9-13]. The "trident molecules" are tripodal alkyl trimethylol derivatives without any cyclic structures but with three-dimensionally arranged coordination sites [14]. Their framework provides high extraction ability and selectivity for certain metal ions. In our previous work, thiol and dithioether derivatives of the trident molecule were prepared to investigate silver extraction [15]. Both types of trident molecules exhibited very strong extraction ability for gold, silver and palladium. The structural effect of the trident framework was only observed on silver extraction with dithioether derivatives, because the affinity for other extraction systems was too strong.

In this study, a trident molecule containing a monoether moiety together with a monopodal molecule has been prepared to investigate silver extraction using ${ }^{1} \mathrm{H}-\mathrm{NMR}$ spectroscopy. The chemical structures of 
the extraction reagents prepared in the previous and present work are shown in Figure 1.

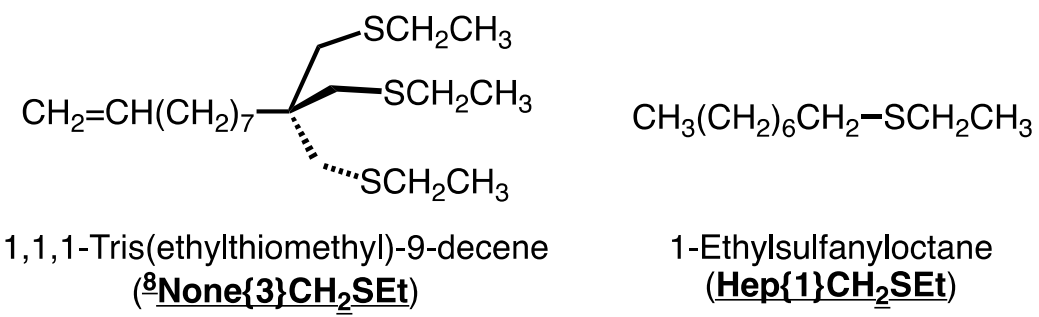

Figure 1. Chemical structures of sulfide extraction reagents employed in this work.

\section{Experimental}

\subsection{Reagents}

1,1,1-Tris(bromomethyl)-9-decene $[11,16-18]$ as a reaction intermediate was prepared in a similar manner to that previously described. The synthetic scheme of the reagents is shown in Figure 2.

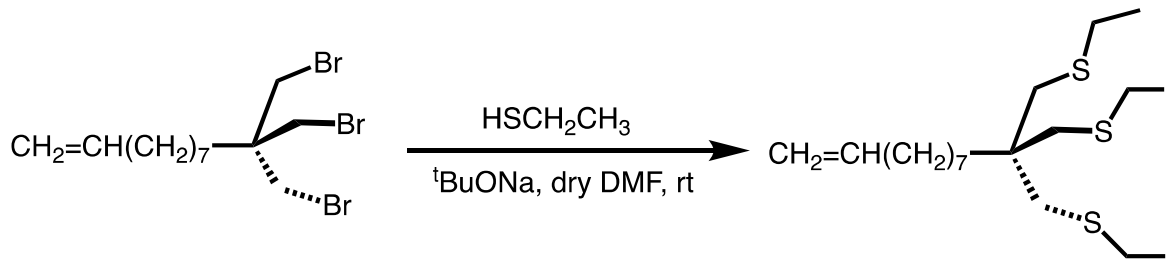

1,1,1-Tris(bromomethyl)-9-decene

( ${ }^{8}$ None $\{3\} \mathrm{CH}_{2}$ SEt)

$$
\begin{aligned}
& \mathrm{CH}_{3}\left(\mathrm{CH}_{2}\right)_{6} \mathrm{CH}_{2} \mathrm{Br} \\
& \underset{\text { tBuONa, dry DMF, rt }}{\stackrel{\mathrm{HSCH}_{2} \mathrm{CH}_{3}}{\longrightarrow}} \mathrm{CH}_{3}\left(\mathrm{CH}_{2}\right)_{6} \mathrm{CH}_{2}-\mathrm{SCH}_{2} \mathrm{CH}_{3} \\
& \text { 1-Bromooctane } \\
& \text { 1-Ethylsulfanyloctane }
\end{aligned}
$$

Figure 2. Synthetic scheme for the extraction reagents.

\section{1,1,1-Tris(ethylthiomethyl)-9-decene $\left({ }^{8} \mathrm{None}\{3\} \mathbf{C H}_{2} \mathbf{S E t}\right)$}

Under a stream of nitrogen, ethyl mercaptane $(3.44 \mathrm{~g}, 55.4 \mathrm{mmol}, 12 \mathrm{eq})$, dry DMF $100 \mathrm{~cm}^{3}$ and sodium t-butoxide $(4.50 \mathrm{~g}, 46.8 \mathrm{mmol}, 10 \mathrm{eq})$ were mixed in an ice bath. Then, 1,1,1-tris(bromomethyl)-9-decene ( $2.00 \mathrm{~g}, 4.76 \mathrm{mmol})$ was added to the mixture. After the temperature was raised to room temperature, the mixture was shaken for $35 \mathrm{~h}$ at room temperature. After the reaction was confirmed to be complete by TLC, methanol was added to deactivate the excess amount of sodium t-butoxide. After evaporation, chloroform $\left(200 \mathrm{~cm}^{3}\right)$ was added to extract the desired compound. The organic solution was washed twice each with $1 \mathrm{M}$ hydrochloric acid $\left(200 \mathrm{~cm}^{3}\right)$, brine $\left(200 \mathrm{~cm}^{3}\right)$ and distilled water $\left(200 \mathrm{~cm}^{3}\right)$. The organic solution was dried over anhydrous magnesium sulfate, filtered, and the solvent was removed in vacuo to give a yellow liquid. Yield 0. $42 \mathrm{~g}(76.2 \%)$, TLC $\left(\mathrm{SiO}_{2}\right.$, hexane : chloroform $=1: 1 \mathrm{v} / \mathrm{v}$ ) $R_{\mathrm{f}}=0.57$, FT-IR (neat) $v_{\mathrm{C}-\mathrm{H}} 2970 \mathrm{~cm}^{-1}, v_{\mathrm{C}=\mathrm{C}} 1640 \mathrm{~cm}^{-1}, v_{\mathrm{C}-\mathrm{s}} 1452 \mathrm{~cm}^{-1}$; ${ }^{1} \mathrm{H}-\mathrm{NMR}\left(300 \mathrm{MHz}, \mathrm{CDCl}_{3}\right.$, TMS, $\left.298 \mathrm{~K}\right) \delta 1.29\left(21 \mathrm{H}, \mathrm{m}, \mathrm{CH}_{2}\left(\mathrm{CH}_{2}\right)_{6} \mathrm{C}+\mathrm{SCH}_{2} \underline{\mathrm{CH}_{3}}\right), 2.04(2 \mathrm{H}, \mathrm{q}$, 
$\left.\underline{\mathrm{CH}_{2}}\left(\mathrm{CH}_{2}\right)_{6}\right), 2.56\left(6 \mathrm{H}, \mathrm{q}, \underline{\mathrm{SCH}}_{2} \mathrm{CH}_{3}\right), 2.65\left(6 \mathrm{H}, \mathrm{s}, \underline{\mathrm{C}}_{\underline{\mathrm{C}}} \mathrm{S}\right), 4.95\left(2 \mathrm{H}, \mathrm{m}, \underline{\mathrm{CH}_{2}}=\mathrm{CH}\right), 5.82(1 \mathrm{H}, \mathrm{m}$, $\mathrm{CH}_{2}=\underline{\mathrm{CH}}$.

\section{1-Ethylsulfanyloctane $\left(\mathrm{Hep}\{1\} \mathrm{CH}_{2} \mathrm{SEt}\right)$}

Under a stream of nitrogen, ethyl mercaptane (1.45 g, $31.1 \mathrm{mmol}$, 2eq), dry DMF $60 \mathrm{~cm}^{3}$ and sodium t-butoxide ( $3.75 \mathrm{~g}, 38.8 \mathrm{mmol}, 2.5 \mathrm{eq})$ were mixed in an ice bath. Then, 1-bromooctane ( $3.00 \mathrm{~g}, 15.5 \mathrm{mmol})$ was added to the mixture. After the temperature was raised to room temperature, the mixture was shaken for $20 \mathrm{~h}$ at room temperature. Methanol was added to deactivate the excess amount of sodium t-butoxide. After evaporation, chloroform $\left(200 \mathrm{~cm}^{3}\right)$ was added to extract the desired compound. The organic solution was washed twice each with $1 \mathrm{M}$ hydrochloric acid $\left(200 \mathrm{~cm}^{3}\right)$, brine $\left(200 \mathrm{~cm}^{3}\right)$ and distilled water (200 $\mathrm{cm}^{3}$ ). The organic solution was dried over anhydrous magnesium sulfate, filtered, and the solvent was removed in vacuo to give a yellow liquid. Yield $1.70 \mathrm{~g}(62.7 \%)$, FT-IR (neat) $v_{\mathrm{C}-\mathrm{H}} 2922 \mathrm{~cm}^{-1}, v_{\mathrm{C}-\mathrm{S}} 1456$ $\mathrm{cm}^{-1}$; ${ }^{1} \mathrm{H}-\mathrm{NMR}\left(300 \mathrm{MHz}, \mathrm{CDCl}_{3}, \mathrm{TMS}, 298 \mathrm{~K}\right) \delta 0.88\left(3 \mathrm{H}, \mathrm{t}, \underline{\mathrm{CH}}_{3}\left(\mathrm{CH}_{2}\right)_{5} \mathrm{CH}_{2}\right), 1.28(13 \mathrm{H}, \mathrm{m}$, $\left.\mathrm{CH}_{3}\left(\mathrm{CH}_{2}\right)_{5} \mathrm{CH}_{2}+\mathrm{SCH}_{2} \underline{\mathrm{CH}_{3}}\right), 1.58\left(2 \mathrm{H}, \mathrm{m}, \mathrm{CH}_{3}\left(\mathrm{CH}_{2}\right)_{5} \underline{\mathrm{CH}}_{2}\right), 2.56\left(4 \mathrm{H}, \mathrm{m}, \underline{\mathrm{CH}_{2}} \mathrm{SCH}_{2} \mathrm{CH}_{3}\right)$.

Other chemicals were of analytical grade and employed without further purification.

\subsection{Extraction of metal ions}

Extractions were carried out by the conventional batch method [14,15]. The organic phase was prepared by dissolving the extraction reagent in chloroform to $5 \mathrm{mM}$ for trident molecules and to $15 \mathrm{mM}$ for the monopodal molecule so that the total amounts of the sulfide groups were the same. The aqueous phase was prepared by dissolving each metal salt in $0.1 \mathrm{M}$ nitric acid or $0.1 \mathrm{M}$ HEPES solution, and by mixing them to adjust to the desired $\mathrm{pH}$ values. Equal volumes of both phases were mixed and mildly shaken at $130 \mathrm{rpm}$ for more than $10 \mathrm{~h}$ at $303 \mathrm{~K}$.

After phase separation, the $\mathrm{pH}$ value and metal concentration in the aqueous solution were measured using a pH meter (Orion, $\varphi 720 \mathrm{~A}$ ), and an atomic absorption spectrophotometer (abbreviated as AAS, Shimadzu, AA-6650) and an inductively coupled plasma atomic emission spectrophotometer (abbreviated as ICP-AES, Shimadzu, ICPS-8100), respectively.

The procedure for determining the extraction reagent concentration dependency was similarly carried out at constant $\mathrm{pH}$ with changing the extraction reagent concentration.

The complexation and extraction behavior of the silver ion in the trident and monopodal molecule systems were also monitored by ${ }^{1} \mathrm{H}-\mathrm{NMR}$ spectroscopy (Jeol, JNM-GX300). Experimental conditions were nearly the same as those described above except for the use of deuterium solvents and the silver concentration. After the attainment of equilibrium, the ${ }^{1} \mathrm{H}-\mathrm{NMR}$ peaks of the extraction reagent molecule in the organic phase were recorded.

\section{Results and Discussion}

\subsection{Extraction of various metals with sulfide type trident molecule}

The time to reach extraction equilibrium was investigated. Silver was selected as the target ion in this work. The effect of the shaking time on the extraction percentage of silver with ${ }^{8} \mathbf{N o n e}\{3\} \mathbf{C H}_{2} \mathbf{S E t}$ is shown in Figure 3. It took $10 \mathrm{~h}$ to reach equilibrium, because the shaking speed was adjusted to just 130rpm. This is why the shaking time was determined to be more than $10 \mathrm{~h}$ for other experiments. 


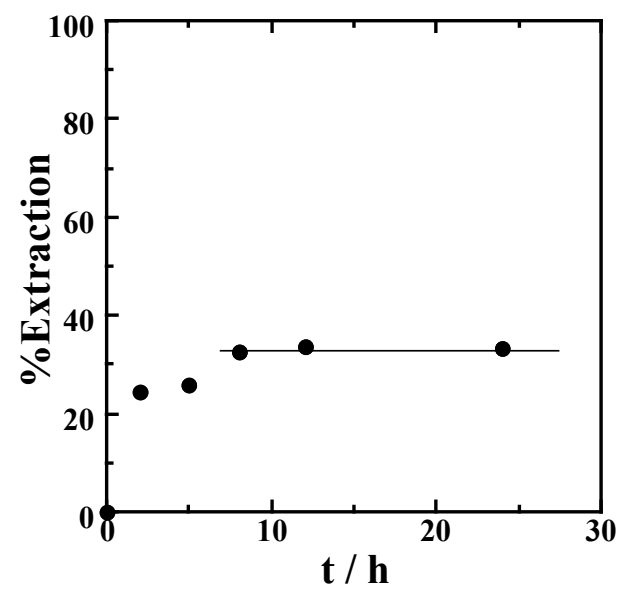

Figure 3. Effect of shaking time on the percentage extraction of silver with ${ }^{8}$ None $\{3\} \mathbf{C H}_{2}$ SEt. [ ${ }^{8}$ None $\left.\{3\} \mathbf{C H}_{2} \mathbf{S E t}\right]_{\text {org }}=5 \mathrm{mM}$, [silver] $=0.1 \mathrm{mM}$ in $0.1 \mathrm{M}$ nitric acid - 0.1 M HEPES solution $(\mathrm{pH}=1.08)$.

The effect of the initial $\mathrm{pH}$ value on the percentage extraction of various metal ions, $\operatorname{Ag}(\mathrm{I}), \mathrm{Pt}(\mathrm{IV})$, $\mathrm{Cu}(\mathrm{II}), \mathrm{Ca}(\mathrm{II}), \mathrm{Li}(\mathrm{I})$ with ${ }^{\mathbf{8}}$ None $\{\mathbf{3}\} \mathbf{C H}_{\mathbf{2}}$ SEt and $\mathbf{H e p}\{\mathbf{1}\} \mathbf{C H}_{\mathbf{2}}$ SEt is shown in Figures 4(a) and (b). The results were similar to those with the thiol and dithioether derivatives of the trident molecules previously reported [15]. The equilibrium $\mathrm{pH}$ values were not significantly changed from the initial $\mathrm{pH}$ values. This means that metal extraction was not driven by an ion-exchange mechanism, but by coordination with the sulfur atoms. Because the sulfide extraction reagents are neutral and each counter anion is required to extract a silver cation. The extraction media contains nitrate anions, which have a low affinity (stability constant) for silver. This means that the extracted species are ion-pair silver complexes. The nitrate concentration decreased with an increase in the $\mathrm{pH}$ value. Although this makes the extraction to be $\mathrm{pH}$ dependent, this behavior is not caused by the proton concentration, but the nitrate. The other possibility is complexation with hydroxyl ions with an increase in the $\mathrm{pH}$ value.
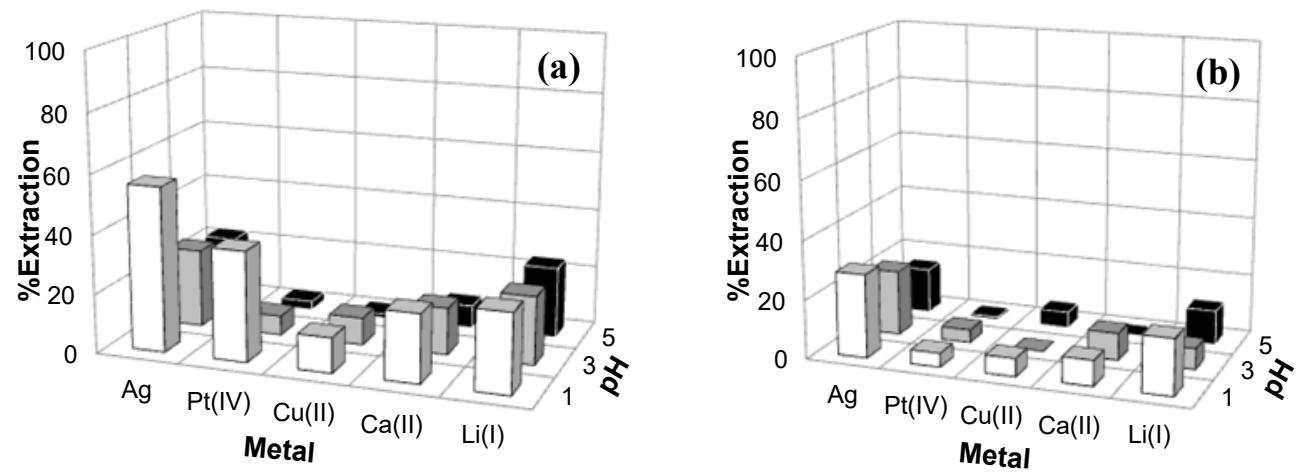

Figure 4. Effect of $\mathrm{pH}$ on the percentage extraction of various metals with (a) ${ }^{\mathbf{8}} \mathbf{N o n e}\{3\} \mathbf{C H}_{2} \mathbf{S E t}$ and (b)Hep $\{\mathbf{1}\} \mathbf{C H}_{2} \mathbf{S E t}$. $\left[{ }^{8} \mathbf{N o n e}\{\mathbf{3}\} \mathbf{C H}_{\mathbf{2}} \mathbf{S E t}\right]_{\text {org }}=5 \mathrm{mM}$, $\left[\mathbf{H e p}\{\mathbf{1}\} \mathbf{C H}_{2} \mathbf{S E t}\right]_{\text {org }}=15 \mathrm{mM}$, [metal $]=0.1 \mathrm{mM}$ each in $0.1 \mathrm{M}$ nitric acid - 0.1 M HEPES solution. 
Silver was quantitatively extracted with thiol and dithioether derivatives of the trident molecules as reported in the previous paper [15], whereas the monothioether ${ }^{8} \mathbf{N o n e}\{3\} \mathbf{C H}_{2} \mathbf{S E t}$ was less able to extract silver due to the small number of the coordinating sulfur atoms. As a comparison of the trident and monopodal reagent shows, the former exhibited a higher extraction percentage than the latter. Since the trident molecule has a longer and unsaturated nonenyl branch, while the monopodal molecule has a shorter and saturated branch, the extraction efficiency of the trident molecule can be greater than that of the monopodal molecule. However, we also consider the "complementary" effect $[15,19,20]$, which causes enhanced uptake by the same plural functional groups.

The dependency of the extraction reagent concentration for both sulfide reagents was investigated to determine the stoichiometry of the extraction reaction. The effect of the extraction reagent concentration for both sulfide molecules on the distribution ratio of silver is shown in Figure 5. The plots for both sulfide reagents lie on straight lines with slopes of $1\left({ }^{8} \mathrm{None}\{3\} \mathrm{CH}_{2} \mathrm{SEt}\right)$ and $2\left(\mathrm{Hep}\{\mathbf{1}\} \mathrm{CH}_{2} \mathrm{SEt}\right)$, respectively. Silver is known to form linear or tetrahedral complexes. The result showed that silver was extracted with two of the three sulfur atoms of ${ }^{8} \mathrm{None}\{\mathbf{3}\} \mathrm{CH}_{2} \mathrm{SEt}$ or with two molecules of $\mathbf{H e p}\{\mathbf{1}\} \mathrm{CH}_{2} \mathrm{SEt}$.

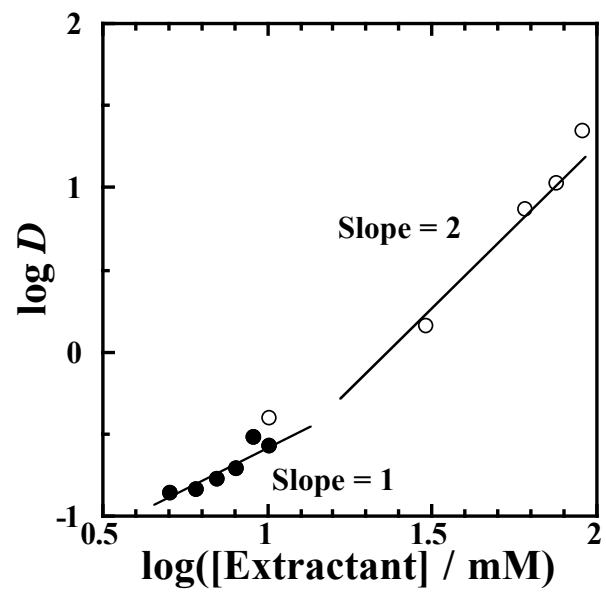

Figure 5. Effect of the extraction reagent concentration on the distribution ratio.

Closed circle : ${ }^{\mathbf{N}} \mathbf{N o n e}\{\mathbf{3}\} \mathbf{C H}_{2} \mathbf{S E t}$, open circle : $\mathbf{H e p}\{\mathbf{1}\} \mathbf{C H}_{2} \mathbf{S E t}$, [silver] $=0.1 \mathrm{mM}$ in 0.1 M HEPES solution, $\mathrm{pH}=5.30\left({ }^{8} \mathbf{N o n e}\{\mathbf{3}\} \mathbf{C H}_{2} \mathbf{S E t}\right), 5.33\left(\mathbf{H e p}\{\mathbf{1}\} \mathbf{C H}_{2} \mathbf{S E t}\right)$.

\section{2 ${ }^{1} \mathrm{H}-\mathrm{NMR}$ study of the silver complexation site with the trident molecule}

In order to elucidate the coordination site of silver with ${ }^{8} \mathbf{N o n e}\{3\} \mathbf{C H}_{2} \mathbf{S E t}$ and $\mathrm{Hep}\{\mathbf{1}\} \mathrm{CH}_{2} \mathrm{SEt}$, the peaks of the ${ }^{1} \mathrm{H}-\mathrm{NMR}$ spectra for both reagents before and after silver loading by changing the silver concentration were checked. The partial peaks of the ${ }^{1} \mathrm{H}-\mathrm{NMR}$ spectra for ${ }^{\mathbf{8}} \mathbf{N o n e}\{\mathbf{3}\} \mathbf{C H}_{\mathbf{2}} \mathbf{S E t}$ and Hep $\{1\} \mathbf{C H}_{2}$ SEt are shown in Figures 6(a) and (b), respectively. The move of the NMR signals for the protons of the methylene groups bounded to the sulfur atoms to a lower magnetic field were observed. This was mainly caused by the decreased electron density with the silver loading on a sulfur atom. For rigid molecules like calixarenes, not only the shifted peaks but also the original peaks were observed, because molecular motion is extremely slow compared with the time scale of the ${ }^{1} \mathrm{H}-\mathrm{NMR}$ spectrometer $[9,10,19,20]$. 
The relationship between the chemical shifts for protons of the methylene groups bounded to the sulfur atoms of ${ }^{8}$ None $\{3\} \mathbf{C H}_{2}$ SEt and $\mathbf{H e p}\{1\} \mathbf{C H}_{2}$ SEt in the ${ }^{1} \mathrm{H}-\mathrm{NMR}$ spectra and the silver loading percentage is shown in Figures 7(a) and (b), respectively. The \%Loading is defined by Eq. (1);

$$
\% \text { Loading }=\frac{\text { Extracted silver ion concentration }}{\text { Initial concentration of extraction reagent }} X 100
$$

It was found that silver loading has a linear relation with the chemical shift at the protons of the methylene groups bounded to the coordinating sulfur atoms of both reagents. In the previous work, divalent lead extraction was investigated with calix[4]arene tetra acetic acid and its corresponding monomer [21]. After the partial loading of lead, both the original and the shifted peaks were observed for the calix[4]arene derivative with changing the integral ratio with lead loading, while the peaks were just shifted with lead loading. This means that the molecular motion of the calix[4]arene derivative is slow and the monomer derivative loads lead quickly. The molecular motions of both extraction reagents are also fast for silver extraction, so that the three functional groups equivalently work together at equilibrium.

In the previous work, it was found that only the far coordinating sulfur atoms relating to silver extraction were related to silver coordination [15]. However, the methylene protons close to the sulfur atoms and to the branched carbon atom were also shifted for the present reagent. It means that the sulfur atoms near the branched carbon atom also relate to the coordination of silver.
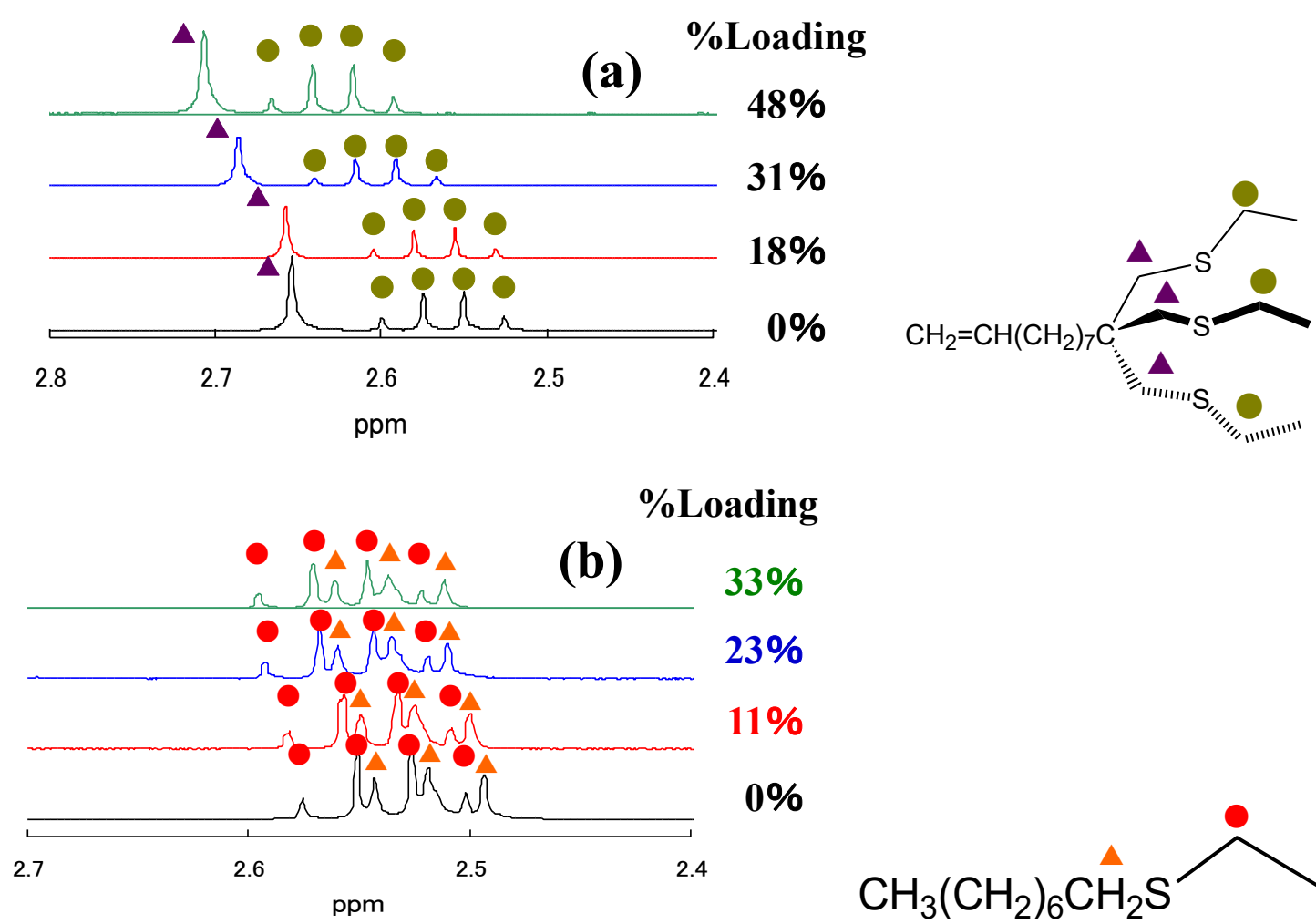

\%Loading

$33 \%$

$23 \%$

$11 \%$

$\mathbf{0} \%$

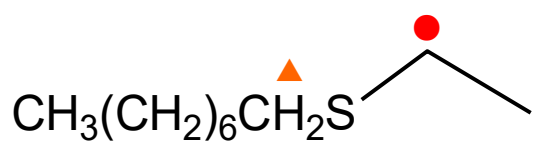

Figure 6. ${ }^{1} \mathrm{H}-\mathrm{NMR}$ spectra of ${ }^{8} \mathrm{None}\{3\} \mathrm{CH}_{2} \mathrm{SEt}$ before and after silver loading on (a) ${ }^{8} \mathbf{N o n e}\{\mathbf{3}\} \mathbf{C H}_{2} \mathbf{S E t}$ $(5 \mathrm{mM})$ and (b)Hep $\{\mathbf{1}\} \mathbf{C H}_{2} \mathbf{S E t}(15 \mathrm{mM})$ in $\mathrm{CDCl}_{3} \cdot\left[\mathrm{Ag}^{+}\right]=0-10 \mathrm{mM}$ in $0.1 \mathrm{M} \mathrm{HNO}_{3}$ of $\mathrm{D}_{2} \mathrm{O}$, phase ratio $=1: 1(\mathrm{v}: \mathrm{v})$. 

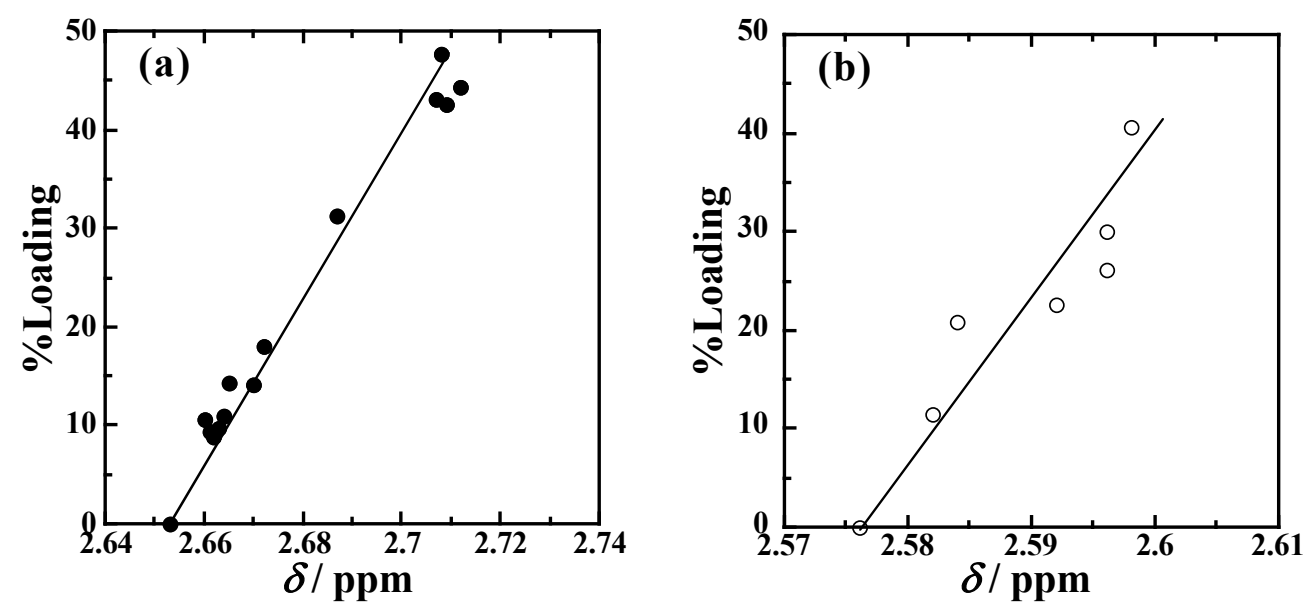

Figure 7. Relationship between peak position of methylene protons next to the sulfur atom and \%Loading of silver on (a) ${ }^{8} \mathbf{N o n e}\{3\} \mathbf{C H}_{2}$ SEt $(5 \mathrm{mM})$ and (b) $\mathbf{H e P}\{\mathbf{1}\} \mathbf{C H}_{2} \mathbf{S E t}(15 \mathrm{mM})$ in $\mathrm{CDCl}_{3}$. [silver] $=10 \mathrm{mM}$ in $0.1 \mathrm{M}$ nitric acid.

The relationship between the difference of the chemical shifts for protons of the methylene groups bound to the sulfur atoms of ${ }^{8}$ None $\{3\} \mathbf{C H}_{2}$ SEt and Hep $\{1\} \mathbf{C H}_{2}$ SEt in the ${ }^{1} \mathrm{H}-\mathrm{NMR}$ spectra and the silver loading percentage is shown in Figure 8. Since the functional groups were the same for both reagents, so the difference in the peak shift was not caused by the functional groups but was a structural effect. The difference in both lines is caused by the contribution of the structural effect of the trident molecule. Silver loading caused the structural change of the trident framework, consequently methylene protons bound to sulfur atoms of the trident molecule were not affected by the electrons of the sulfur atoms. This causes a lower magnetic field shift than the monopodal methylene protons.

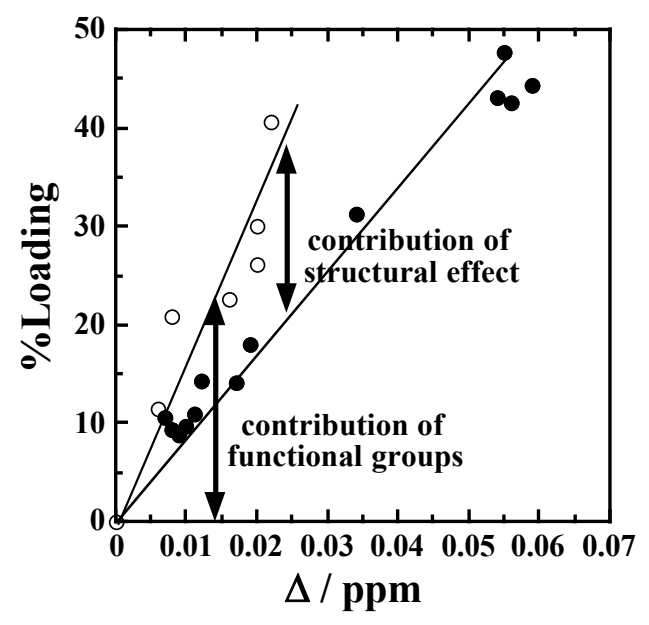

Figure 8. Relationship between the difference in the peak positions before and after silver loading for methylene protons next to a sulfur atom and \%loading of silver on (closed circle)

${ }^{8}$ None $\{3\} \mathrm{CH}_{2}$ SEt and (open circle) $\mathrm{HeP}\{1\} \mathrm{CH}_{2} \mathrm{SEt}$. 


\section{Conclusion}

Sulfide derivatives of tripodal extraction reagents and a monopodal reagent have been prepared to investigate their extraction behavior for silver. Both derivatives exhibited a lower extraction ability for silver compared with the thiol and dithioether derivatives of the trident reagents. The extraction stoichiometry was confirmed by slope analysis. The coordination sites of the trident and monopodal reagents were confirmed by ${ }^{1} \mathrm{H}-\mathrm{NMR}$ spectra before and after silver loading. The site of the sulfide trident reagent was different from that of the dithioether derivative whose sulfur atoms further from the branched carbon atom can only coordinate to silver as reported in the previous paper.

\section{References}

1) K. Ohto, Ion Exch. Solvent Extr., 21, 81-127 (2014).

2) R. G. Pearson, J. Am. Chem. Soc., 85, 3533-3539 (1963).

3) M. Iwakuma, T. Oshima, Y. Baba, Solvent Extr. Res. Dev., Jpn., 15, 21-35 (2008).

4) H. Narita, M. Tanaka, J. MMIJ, 127, 175-181 (2011). (in Japanese)

5) D. Sevdic, H. Meider, J. Inorg. Nucl. Chem., 39, 1409-1413 (1977).

6) K. Saito, Y. Masuda, E. Sekido, Anal. Chim Acta, 151, 447-455 (1983).

7) E. Sekido, K. Chayama, M. Muroi, Talanta, 32, 797-802 (1985).

8) T. Tsend-Ayush, M. Wenzel, K. Gloe, K. Gloe, J. J. Weigand, Y. V. Fedorov. O. A. Fedorova, S. P. Gromov, P. G. Plieger, Solvent Extr. Res. Dev., Jpn., 23(1), 31-41 (2016).

9) K. Ohto, E. Murakami, T. Shinohara, K. Shiratsuchi, K. Inoue, M. Iwasaki, Anal. Chim. Acta, 341, 275-283 (1997).

10) K. Ohto, H. Yamaga, E. Murakami, K. Inoue, Talanta, 44, 1123-1130 (1997).

11) H. Furugou, K. Ohto, H. Kawakita, H. Harada, K. Inoue, Ars Separatoria Acta, 5, 68-75 (2007).

12) Y. Ueda, S. Morisada, H. Kawakita, K. Ohto, Solvent Extr. Res. Dev., Jpn., 20, 53-63 (2013).

13) K. Ohto, Y. Ueda, R. R. Sathuluri, H. Kawakita, S. Morisada, K. Inoue, Silver Recovery from Assorted Spent Sources: Toxicology of Silver Ion, Nova Science Publishers, NY, Chapter 9, 275-301 (2018)

14) R. Yamaguma, A. Yamashita, H. Kawakita, T. Miyajima, C. Takemura, K. Ohto, N. Iwachido, Sep. Sci. Technol., 47, 1303-1309 (2012).

15) K. Ohto, H. Furugou, T. Yoshinaga, S. Morisada, H. Kawakita, K. Inoue, Solvent Extr. Res. Dev., Jpn., 24(2), 77-88 (2017).

16) H. B. Schurink, Org. Synth. Coll., 1, 425-427 (1932).

17) F. Hein, R.Burkhardt, Chem. Ber., 90, 928-935 (1957).

18) K. Ohto, H. Nakagawa, H. Furutsuka, T. Shinohara, T. Nakamura, T. Oshima, K. Inoue, Solvent Extr. Res. Dev., Jpn., 11, 121-134 (2004).

19) T. Yoneyama, H. Sadamatsu, S. Kuwata, H. Kawakita, K. Ohto, Talanta, 88, 121-128 (2012).

20) H. Sadamatsu, T. Hanada, S. Morisada, H. Kawakita, K. Ohto, J. Incl. Phenom. Macrocycl. Chem., 84(1), 87-97 (2016).

21) K. Ohto, Y. Fujimoto, K. Inoue, Anal. Chim. Acta, 387(1), 61-69 (1999). 